\title{
Turismo e Desastres: o caso das enchentes e deslizamentos na destinação turística Costa Verde e Mar - Santa Catarina (Brasil)
}

\section{Tourism and Disaster: the case of floods and landslides in the tourist destination and Costa Verde e Mar - Santa Catarina (Brazil)}

\author{
Marcelo Mariano Rocha (ROCHA, M. M.) ${ }^{*}$ e \\ Marcos Antônio Mattedi (MATEDI, M. A.) ${ }^{* *}$
}

RESUMO - No presente trabalho se apresentam as implicações dos desastres sobre a atividade turística, em especial a abordagem da destinação turística Costa Verde e Mar, em Santa Catarina (Brasil). A destinação encontra-se localizada na Bacia Hidrográfica do Vale do Itajaí, uma região suscetível a desastres, e com potencial para provocar sérios impactos para o trade ${ }^{1}$ turístico. Para analisar essa problemática, a pesquisa teve como metodologia o levantamento de dados qualitativos e quantitativos, bem como a análise de documentos oficiais sobre o turismo e os desastres em Santa Catarina. Concluiu-se que a atividade turística explorada na destinação possuiu total condição de ser afetada pelos desastres em virtude das condições ambientais, geológicas e hidrológicas existentes na região do Vale do Itajaí. Desta forma, a efetivação desse fenômeno poderia proporcionar um grande prejuízo para o trade, bem como para a economia da destinação turística.

Palavras-Chave: Turismo; Gestão; Vulnerabilidade; Suscetibilidade; Destinação Turística; Desastres.

ABSTRACT - This paper aims to show the implications of disasters on tourism, focusing on the tourist destination Costa Verde e Mar, at Santa Catarina. The destination is located at the hydrographic basin of Vale do Itajaí, a susceptible area for disasters and with potential to cause serious impacts on the touristic trade. To analyze this problem, this research had as its methodology the survey of qualitative and quantitative data, as well as the official documents analysis about the tourism and the disaster in Santa Catarina. Therefore, it may be concluded that tourism activity

\footnotetext{
* Formação: Graduação em Turismo (Bacharelado) pela Faculdade de Presidente Prudente (UNIESP); Especialização pelo Programa de Pós-Graduação em Geografia FCT UNESP em Tecnologia de Informação e Comunicação, Educação Ambiental e Gerenciamento de Recursos Hídricos; Mestrado em Desenvolvimento Regional pelo Programa de Pós-Graduação em Desenvolvimento Regional FURB (Blumenau). Atividade profissional: Docente-Secretária de Educação de Santa Catarina. Endereço físico para correspondência: Rua Manoel José da Costa, n. 326-A. CEP: 88370-250 - Navegantes - Santa Catarina/SC - Brasil. E-mail: mmariano.rocha@gmail.com

** Formação: Graduação em Ciências Sociais FURB; Mestrado em Sociologia Política UFSC; Doutorado em Ciências Sociais pela Universidade Estadual de Campinas e estágio pós-doutoral no Centre de Sociologie in L'innovation - ENMP/Paris. Atividade profissional: Docente - FURB. Endereço físico para correspondência: Rua Max Hering n. 55, ap. 504. CEP: 89012510 - Blumenau - Santa Catarina/SC Brasil. E-mail: mattediblu@gmail.com

${ }^{1} \mathrm{O}$ trade turístico é o conjunto de equipamentos constituintes do produto turístico, caracterizado como meios de hospedagem, bares e restaurantes, agências de viagens e turismo, empresas de transporte e todas as atividades comerciais periféricas ligadas direta ou indiretamente à atividade turística.
} 
exploited at the location possesses conditions to be affected by environmental disasters, such as geological and hydrological conditions existing in Vale do Itajaí region. Thus, the effectivity of this phenomenon could provide a great loss to the trade as well as to the touristic destination's economy.

Key words: Tourism; Management; Vulnerability; Susceptibility; Tourist Destination; Disaster. 


\section{INTRODUÇÃO}

O setor turístico vem assumindo uma importância fundamental no desenvolvimento econômico de determinadas localidades. Assim, esse setor tem sido tratado como segmento estratégico em função do seu poder gerador de divisas, principalmente em relação a espaços que apresentam condições reais para a exploração de seus recursos naturais ou socioculturais. No entanto, tal desenvolvimento é comprometido pela vulnerabilidade a intempéries; assim "o setor do turismo poderá ser exposto aos impactos dos desastres naturais e, desta forma, muitos destinos estarão em riscos a partir desses fenômenos" (GHADERI; MAT SOM; HERDERSON, 2015, p. 399).

Muitas localidades, que se tornaram destinações turísticas por possuírem elementos naturais e/ou culturais destinados à comercialização, podem apresentar alguma característica de vulnerabilidade que, associadas a práticas ambientais insustentáveis, possibilitam uma maior probabilidade de ocorrência de desastres. O setor turístico, por ser muito suscetível a intervenções externas, tais como guerras, epidemias, crises econômicas, aspectos climáticos, entre outros, pode gerar impactos negativos ao setor. Segundo Toubes e Brea Fraiz (2012), quando há uma catástrofe natural em um destino turístico, ações operacionais devem ser feitas de forma a obter uma rápida recuperação, evitando, assim, que a imagem do destino sofra impactos negativos. Dessa forma, as estratégias desenvolvidas pela gestão de crises em um destino turístico devem ser suficientemente amplas e abrangentes.

Territórios transformados em destinações turísticas em função dos atrativos existentes, quando associados a características que são capazes de gerar desastres, podem se tornar um fator preocupante para o desenvolvimento da atividade turística. Existem no Brasil e no mundo destinações que, além de apresentarem todos os elementos necessários para o desenvolvimento do turismo, vêm manifestando elementos que podem causar desastres e, com isso, trazer prejuízos às atividades econômicas do local, como, por exemplo, a vulnerabilidade socioambiental.

As intempéries em destinos turísticos são altamente nocivas a ele porque podem gerar crises no setor em decorrência dos possíveis impactos econômicos para toda a cadeia turística. Assim, os desastres são vistos como passíveis de causar prejuízos ao 
setor turístico, o que faz com que órgãos públicos e entidades privadas devam se planejar em relação a essa questão, de forma a mitigar os possíveis problemas decorrentes desse fenômeno (TOUBES; BREA FRAIZ, 2011), principalmente para áreas suscetíveis a intempéries.

No estado de Santa Catarina encontra-se a destinação turística denominada de Costa Verde e Mar, uma localidade de grande destaque no turismo em função das belezas naturais. No entanto, uma parcela dos municípios integrantes da destinação encontra-se dentro da Bacia Hidrográfica do Rio Itajaí Açú, que possui suscetibilidade a desastres devido às condições físicas existentes no local (ESTADO DE SANTA CATARINA, 2009). Assim exposto, esclarece-se que a presente pesquisa teve como pressuposto metodológico a realização de um estudo de caso da Destinação Turística Costa Verde e Mar, evidenciando dados através de referências bibliográficas, de pesquisa documental sobre desastres e de levantamento de dados quantitativos sobre fenômenos da natureza, associados à ação antrópica. Dessa forma, pretendeu-se realizar uma análise e apresentar elementos sobre a relação e a suscetibilidade dessa destinação turística à iminência de desastres sobre a Costa Verde e Mar, em virtude de sua localização e de seu histórico de intempéries, e, consequentemente, da região turística ser detentora de um grande fluxo de turistas anualmente, movimentando toda uma cadeia econômica do turismo regional.

\section{O IMPACTO DOS DESASTRES NA ATIVIDADE TURÍSTICA}

O avanço da expansão do fenômeno turístico vem permitindo que diversas regiões com potenciais turísticos possam ter sua economia fortalecida através do setor do turismo. Dessa forma, os economistas vislumbraram, na atividade turística, um importante gerador de renda, que contribui para o crescimento econômico e para a elevação das taxas de desenvolvimento de diferentes regiões. Dentro desse cenário, muitas localidades têm sua economia alicerçada no segmento do turismo, assim como existem regiões que possuem, na atividade do turismo, uma fonte de recursos financeiros provenientes da demanda turística. Assim, pode-se afirmar que o setor turístico é inerente ao desenvolvimento territorial. Devido às condições econômicas, 
como, por exemplo, geração de emprego, fortalecimento da economia local/regional que o setor proporciona, territórios que possuem bens para a exploração dos seus espaços passaram a direcioná-los como atrativos para consumo (turístico), como, por exemplo, "os parques temáticos como: o Beto Carrero Word, em Penha, no litoral de Santa Catarina; o Beach Park, próximo a Fortaleza, no Ceará e o Complexo turístico Blue Tree Park, no Cabo de Santo Agostinho, em Pernambuco" (OURIQUES, 2005, p. 133).

No entanto, as destinações turísticas que apresentam aspecto de vulnerabilidade, passam a correr perigo sobre a iminência de intempéries. Quando desastres atingem algum destino turístico, eles podem desestruturar toda a dinâmica existente no setor e, assim, a capacidade de resiliência, ou seja, de recuperação econômica de determinada destinação turística, juntamente com toda sua cadeia turística, correndo o risco de ficar comprometida. Na última década, uma série de desastres naturais afetaram severamente algumas rotas de turismo. Os exemplos mais proeminentes incluem o tsunami do Oceano Índico em 2004, o furacão Katrina nos Estados Unidos em 2005, o tsunami de Samoa em 2009, as inundações na Austrália, que ocorreram entre 2010 e 2011, e os terremotos em Christchurch, na Nova Zelândia, entre 2010 e 2011. (BECHEN; HUGHEY, 2013).

Os impactos dos desastres sobre a atividade turística podem abranger a infraestrutura física (estradas, meios de hospedagem, meios de transportes, dentre outros elementos), o marketing turístico (rádio e TV), a perda do fluxo de turistas, a diminuição da arrecadação, entre outros. Isso gera impactos econômicos sem precedentes à recuperação do setor do turismo. De acordo com Maditinos e Vassiliadis (2008), o turismo é muitas vezes descrito como uma atividade econômica frágil, em que a demanda por viagens é altamente suscetível a inúmeros choques, tais como guerras, epidemias de doenças mortais, doenças contagiosas, incidentes de terrorismo, flutuações econômicas, instabilidade da moeda, crises de energia, e assim por diante.

Em consequência do avanço do processo tecnológico e do crescimento vertiginoso do mercado turístico, os locais que foram turistificados passaram a ser vendidos comercialmente e, consequentemente, passaram a atrair visitantes. Assim, o setor do turismo se tornou dependente de um ecossistema intacto e de estruturas institucionais que podem responder às necessidades da população de um local e de visitantes. Portanto, a prevenção de catástrofes e gestão delas (por desastres naturais e 
provocados pelo homem) deve ser uma parte essencial do plano de gestão turística para qualquer destino (MADITINOS; VASSILIADIS, 2008). Dentro disso, "no turismo, as preocupações de estabelecer políticas para o setor só aparecem quando este adquire importância econômica ou quando começa a causar transtornos [...]” (SOLHA, 2006, p. 90).

As questões que envolvem a gestão dos desastres sobre a atividade turística nas políticas públicas podem se tornar um fator determinante para o sucesso e fracasso de certas localidades turísticas que apresentem elementos de vulnerabilidade. "O turismo é altamente sensível a crises e elas se agravam quando associadas a desastres e, um sistema de proteção aos turistas e de recuperação das áreas turísticas deve ser implementado pelas autoridades competentes" (ZUCCO; MAGALHÃES, 2011, p. 603). Dessa forma, os impactos podem atingir diretamente aos turistas e, para minimizálos, é necessário que ações emergenciais sejam implementadas. Como enfatizam Maditinos e Vassiliadis (2008, p. 68):

[...] os desastres aumentam as preocupações de turistas com segurança e proteção colocando pressão crescente sobre planejadores e gestores envolvidos com o turismo, impelindo-os a analisar o impacto das catástrofes sobre essa indústria e a desenvolver estratégias para lidar com as crises. A redução da iminência do perigo de um desastre depende, sobretudo, de ações pautadas e estabelecidas na concepção de uma nova cultura, enfatizada no campo ambiental e social, visando uma melhor integração entre os seres humanos e ambiente.

No entanto, fatores como a intervenção através de planejamento e gestão dos desastres no segmento do turismo, por parte das esferas governamentais, poderiam trazer benefícios para a diminuição da suscetibilidade a desastres e, consequentemente, para o aumento da capacidade de resiliência em diversas áreas; entre elas, o setor do turismo. Assim, é necessário realizar uma abordagem relevante e sistemática, do ponto de vista de ações por parte do poder público na promoção, divulgação e planejamento da atividade turística.

Adotar quesitos como a gestão dos desastres na atividade turística em determinada localidades, como medida preventiva contra possíveis impactos, pode se tornar uma ferramenta indispensável para muitas destinações turísticas que apresentam alguma característica de vulnerabilidade a desastres. Desta forma, essa questão é enfatizada por Kobiyama (2006, p. 31) que em seus estudos destaca que: 
Dentro dessas linhas de raciocínio o desastre está muito vinculado à questão da prevenção e do planejamento por parte dos responsáveis a fim de diminuir os riscos de um evento calamitoso. Quando um evento desse porte ocorre em uma destinação turística, os efeitos são sentidos a curto, médio e longo prazo, trazendo problemas e principalmente prejuízos para a localidade turística.

Assim, localidades turísticas que são afetadas por esses eventos podem ter seus fluxos turísticos prejudicados em função da interferência desses fenômenos sobre o local. A implementação de ações e de planejamento em longo prazo contra os desastres pode esbarrar em questões de interesse tanto privado (empresas particulares), quanto estatal (esferas municipal, estadual e federal), e assim se tornar fator determinante para a falta de gestão e de prevenção na relação dos desastres na atividade turística.

Esses interesses podem se sobressair sobre as necessidades de implantação de ações de cunho preventivo contra esses fenômenos. A atividade turística é alicerçada em um segmento econômico sazonal e é dependente de fatores externos, como, por exemplo, clima e economia. As ações, como promoção e divulgação dos destinos turísticos, podem trazer reflexos imediatos na dinâmica do setor, principalmente nas questões que envolvem a entrada de divisas. Assim, o turismo "pode ser encarado como o último milagre do capitalismo mundial em sua jornada. É inegável que a introdução do turismo na periferia acabou por gerar ilhas de prosperidade, criando um circuito privilegiado de consumo e padrão" (OURIQUES, 2005, p. 136).

A partir do momento em que o setor turístico é afetado por alguns desastres como uma catástrofe natural, um acidente industrial, um ataque terrorista, uma epidemia, uma crise econômica, entre outros, o cenário turístico passará a demonstrar instabilidade, em consequência dos impactos gerados por esses fenômenos e, assim, trará prejuízos das mais diversas ordens, principalmente financeiros, um exemplo é a destinação turística de Kelowna (Canadá) que experimentou um gravíssimo incêndio florestal (HYSTAD; KELLER, 2008).

Assim, pode-se perceber que as relações que envolvem o setor turístico e as questões sobre os desastres são complexas e muito abrangentes. Economias de muitos territórios são sustentadas basicamente pela exploração e comercialização da atividade turística. No entanto, muitas localidades podem apresentar algum tipo de vulnerabilidade quando associadas a fatores externos, tais como: aspectos climatológicos, físicos, dentre outros, o que pode gerar intempéries que afetarão diretamente o trade turístico. Pode-se citar como exemplo a destinação turística Costa 
Verde Imperial, localizada na região Serrana do Rio de Janeiro. Segundo Guimarães et al. (2014) a região apresenta um histórico de intempéries, onde diversos municípios foram afetados em função da grande quantidade de chuva, causando enchentes, inundações e escorregamentos de encostas, deixando um rastro de mortes e milhões em prejuízos financeiros.

Sendo assim, o turismo se torna uma atividade vulnerável a mudanças repentinas, o que o faz dependente de planejamento e gestão eficientes, como, por exemplo, um plano de contingência. Segundo Nascimento et al. (2013), essa ação ajuda a diminuir os impactos negativos nas regiões que buscam o desenvolvimento dessa atividade, facilitando a participação da comunidade e das iniciativas privada e pública no processo de tomada de decisão dos municípios, ou seja, contribuindo para o desenvolvimento do turismo e minimizando os impactos ambientais.

\section{A PROBLEMÁTICA DOS DESASTRES EM DESTINAÇÕES TURÍSTICAS}

A necessidade da sociedade de ter uma atividade de lazer em função das relações de trabalho acabou sendo fator preponderante ao desenvolvimento turístico. (OURIQUES, 2005). A partir desse contexto, a atividade turística está baseada, principalmente, na exploração dos recursos naturais e culturais inseridos no espaço geográfico, que ao longo do tempo foi sendo produzido pelo homem através das interrelações pessoais com o meio abiótico e biótico circundante. Analisado sob esse prisma, o conhecimento sobre os espaços turísticos se constitui como elemento essencial para o desenvolvimento do seu trade. No setor de turismo se procura comercializar os potenciais turísticos de determinado território e, dessa forma, busca-se vender esses espaços para indivíduos dispostos a consumi-los, criando, assim, relações com o meio (espaço e autóctones) e com influência externa (turistas), atraindo fluxo de divisas para as localidades.

Dentro da comercialização de espaços, entre eles os naturais, surgem destinações turísticas e localidades que detêm toda condição necessária para a realização da atividade turística. Essas destinações exercem um importante papel na economia da região em que a atividade está inserida, contribuindo para o desenvolvimento regional. 
"Muitas destinações turísticas, além de contar com todo atrativo necessário para o desenvolvimento do segmento do turismo, contam também com a iminência e muitas vezes com a consolidação de fenômenos como os desastres” (TSAI; CHEN, 2010, p. 478). Fatores como localização geográfica, características físicas (geológicas, geomorfológicas e hidrológicas), bem como questões de vulnerabilidades, podem se tornar fatores que condicionam tais fenômenos, de forma a atingir as destinações turísticas.

Observa-se um número crescente de catástrofes e crises que afetam o setor do turismo, como incidentes naturais influenciados pela ação humana. (FAULKNER, 2001). Muitas destinações turísticas, nacionais e internacionais, vêm apresentando a iminência dos desastres como fator preocupante sobre o turismo, pois isso pode afetar a economia dessas localidades e, consequentemente, desestruturar toda a dinâmica do seu trade. Dentro desse contexto, podem-se citar exemplos de destinações turísticas que vêm convivendo com a ameaça e até mesmo com a efetivação desses fenômenos. Algumas destinações na Ásia como, por exemplo, Banquecoque, capital da Tailândia, sofreu em 2011 fortes inundações (GHADERI; MAT SOM; HERDERSON, 2015) e no Brasil, a região Serrana do Rio de Janeiro, na destinação Costa Verde Imperial sofreu com a efetivação de intempéries, causando enormes prejuízos materiais e financeiros (GUIMARÃES, 2014).

Alguns pesquisadores internacionais, como Chung-Hun Tsai (2010), Cheng-Wu Chen (2010), Perry W. Hystad (2008), Peter C. Keller (2008), Maditinos (2008), Vassiliadis (2008) passaram a realizar pesquisas sobre as relações entre os desastres, sob a ótica do setor do turismo e seus impactos. Alguns autores como Chung-Hung Tsai (2010; 2011) e Cheng-Wu Chen $(2010 ; 2011)$ concentraram suas pesquisas na Ásia, focando sua área de estudo nas destinações turísticas e em seus impactos associados a desastres, como exemplo a ilha de Taiwan, em 2010. Em sua pesquisa mais recente, Tsai e Chen (2010) evidenciaram uma problemática existente na ilha, na qual o turismo passou a ser fomentado pelo mercado turístico em localidades geograficamente inadequadas para o desenvolvimento dessa atividade, colocando em perigo o setor turístico e os turistas, devido ao grau de suscetibilidade a desastres existente nesse território. 
Segundo Tsai e Chen (2010), para explorar plenamente os recursos naturais, a maioria dos operadores de turismo, naturalmente, querem construir instalações turísticas perto de locais com belas paisagens, muitas vezes ao lado de montanhas ou à beira-mar. Os autores salientam que o "problema nessas regiões são caracterizados pelo alto risco de desastres e falta de recursos para o trabalho de socorro ao público" (TSAI; CHEN, 2010, p. 471). Assim, os aspectos de vulnerabilidade a desastres podem se tornar condições secundárias dentro do cenário turístico. Portanto, questões como a segurança, a gestão e a prevenção não são colocados em pauta nas discussões.

Os fatores supracitados são apresentados pelos autores de forma enfática, tendo em vista que "Taiwan encontra-se localizada na Zona Sísmica Circum-Pacífico e, portanto, área propensa a terremotos frequentes. Nos últimos anos, tem sido em média, mais de 200 abalos sísmicos por ano" (TSAI; CHEN, 2010, p. 472). Devido à suscetibilidade física sobre a efetivação de um desastre provocado por abalos sísmicos, a ilha de Taiwan apresenta reais elementos de que o desenvolvimento do turismo precisa ser revisto, levando em consideração essas condicionantes. Dentro das conclusões propostas pelos autores, pode-se destacar que:

\begin{abstract}
A única maneira de diminuir a quantidade de danos e diminuir o impacto sobre as pessoas, empresas e governo, é contar com o preparo de redução de desastres ou medidas de diminuição do risco. É necessário identificar, avaliar, controlar e transferir os riscos dos desastres para a indústria do turismo através de uma abordagem adequada de gestão dos desastres. (TSAI; CHEN, 2010, p. 479).
\end{abstract}

Dessa forma, os autores puderam constatar que "existem muitos equipamentos turísticos localizados em regiões que também estão sujeitas a taxas de alta frequência de desastres naturais" (TSAI; CHEN, 2010, p. 478), tais como terremotos. A destinação turística em Taiwan demonstra que o turismo tem em sua concepção a forma da exploração sem planejamento turístico. Esse fator não leva em consideração as atenuantes existentes, esquecendo-se das possíveis consequências ao setor e principalmente para aqueles que o consomem enquanto mercadoria, ou seja, os turistas.

Pode-se citar outra destinação turística que foi afetada por esse fenômeno:

O fato aconteceu no Canadá durante o verão de 2003, perto de Kelowna, British Columbia. Durante o verão de 2003, Kelowna experimentou um gravíssimo incêndio florestal. $\mathrm{O}$ que se tornou conhecido como Incêndio Florestal Okanagan Mountain Park. O fato foi iniciado em 16 de agosto, com 
duração de quase um mês, onde o fogo forçou a evacuação de 26 mil moradores e destruiu 238 casas particulares e uma parte substancial da infraestrutura do turismo regional. A destinação turística é uma crescente no setor do turismo que concentra lagos e montanhas, oferecendo turismo rural, atrativos como vinhos, músicas, artes (HYSTAD; KELLER, 2008, p 140141).

Segundo levantamento realizado sobre as hipóteses, a capacidade de gestão e a prevenção contra o desastre dessa destinação, ficou evidenciado que não houve preparação por parte dos setores responsáveis em propor medidas de gestão ao setor para que fosse possível integrar ações contra esse fenômeno. Dentro dos resultados obtidos no estudo de caso, foram selecionados alguns aspectos sobre a falta de gerenciamento, que foram evidenciados pelos autores, sobre o desastre que proporcionou diversos impactos para o seu trade turístico. Dentro disso, segundo os autores Hystad e Keller (2008, p. 155), destacam-se alguns elementos como:

I - A indústria do turismo foi mal preparada para um grande desastre de incêndios florestais, apesar da probabilidade de sua possível ocorrência; II - A maiorias das empresas relataram uma preparação passiva e reativa, bem como uma resposta "esperar para ver";

III - Empresas de pequeno porte e do setor de alojamento pareciam ser as mais suscetíveis a resultados negativos do desastre;

IV - As autoridades locais responsáveis pelo marketing turístico, estavam inicialmente despreparados, mas assumiram o controle efetivo das responsabilidades de comunicação e empenharam-se em transformar a cobertura da mídia inicial negativa em algo mais positivo e informativo; V - Um número de empresas continuaram a serem afetadas pelo desastre e estavam preocupadas com os impactos à longo prazo.

Dentro dos resultados da pesquisa sobre a destinação turística, o Parque Florestal em Kelowna, no Canadá, se destacou a ausência de um trabalho de gestão contra desastres, em função da iminência de um incêndio, levando em consideração as características citadas acima. Segundo Toubes e Fraiz Brea (2012), as estratégias de gestão de crises desenvolvidas em um destino turístico devem ser suficientemente amplas e abrangentes quando aplicadas em diferentes situações, não se limitando a casos específicos também. Elas devem levar em conta os elementos de prevenção antes da crise, pois são uma parte essencial do planejamento da gestão estratégica contra os 
desastres, uma vez que a preparação para um hazard ${ }^{2}$ em potencial é a chave para uma recuperação rápida e eficaz.

Os exemplos que foram apresentados das destinações turísticas na Ásia (Taiwan) e na América do Norte (Kelowna/Canadá) demonstram que os desastres faziam parte do cotidiano da atividade turística nessas localidades. Nesses exemplos, pôde-se perceber que questões de intempéries eram evidentes em virtude das características existentes em Taiwan e no Canadá. Dessa forma, em ambos os casos, a gestão e a prevenção dos desastres eram necessárias perante as condições existentes; no entanto, ficou evidente que esses aspectos não estiveram associados ao desenvolvimento do turismo. Esse fator coloca em perigo a continuidade do desenvolvimento do turismo nessas destinações, já que esse fenômeno prejudica a capacidade de resiliência das destinações, além de salientar a falta de segurança dos turistas em decorrência da ausência de um sistema de gestão que possa coordenar essa problemática.

\section{A DESTINAÇÃO TURÍSTICA: COSTA VERDE E MAR}

Santa Catarina se destaca no cenário turístico em função da diversidade de suas paisagens naturais. Assim, o estado criou, através de institucionalizações de regiões turísticas como medida de desenvolver o turismo de forma regional e promover a expansão de seu trade. (ESTADO DE SANTA CATARINA, 2011). O mapa abaixo apresenta a zona da destinação turística Costa Verde e Mar, que se encontra localizada em um território constituído pelos seguintes municípios: Luís Alves, Balneário Piçarras, Penha, Ilhota, Itajaí, Camboriú, Balneário Camboriú, Itapema, Porto Belo e Bombinhas (ESTADO DE SANTA CATARINA, 2011).

\footnotetext{
${ }^{2}$ Hazard: são processos ou fenômenos naturais que ocorrem na biosfera, podendo constituir um evento danoso e serem modificados pela atividade humana, tais como a degradação do ambiente e a urbanização (KOBIYAMA, 2006).
} 
FIGURA 1 - LOCALIZAÇÃO DOS MUNICÍPIOS QUE INTEGRAM A DESTINAÇÃO DA COSTA VERDE E MAR

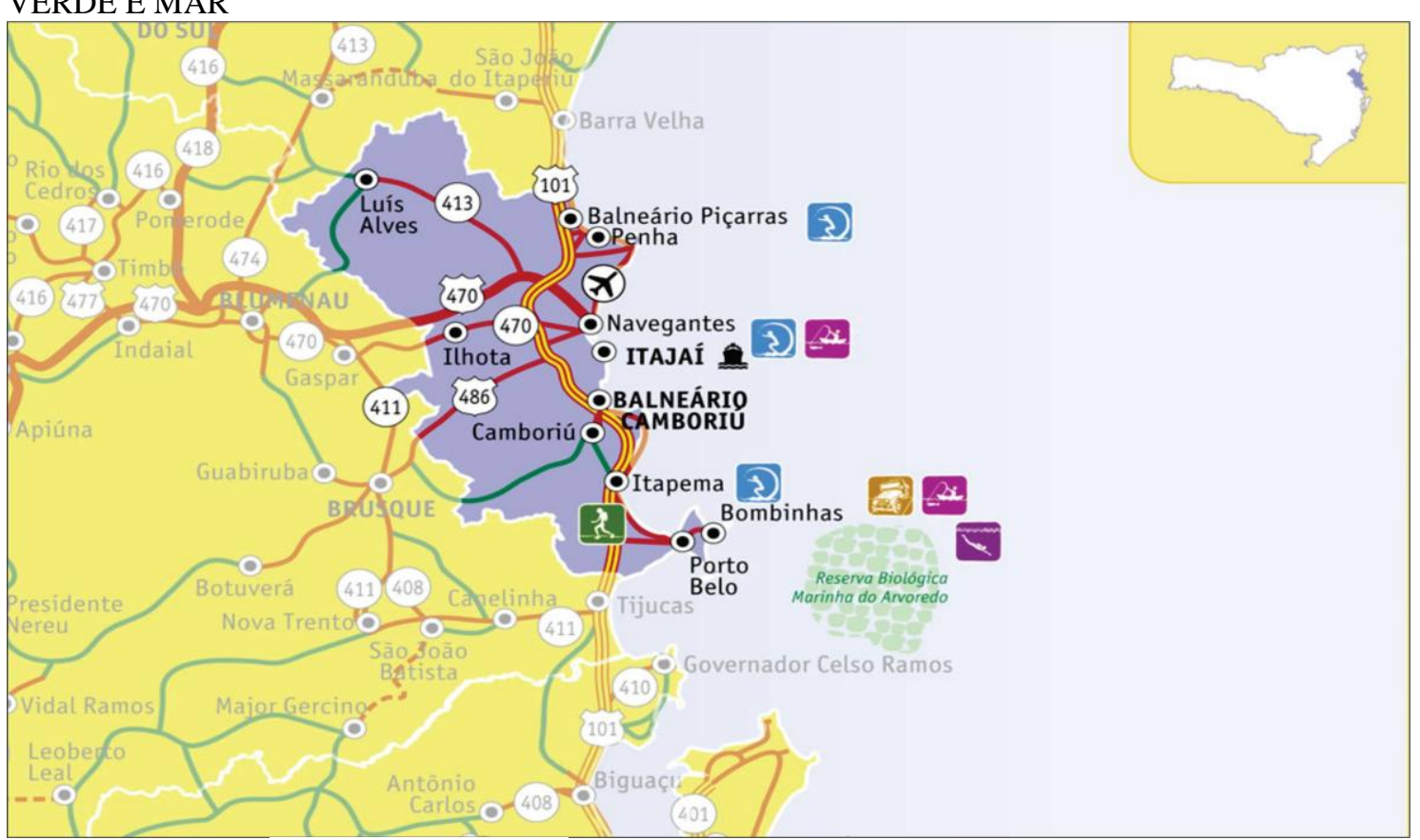

FONTE: Estado de Santa Catarina (2011).

A destinação turística Costa Verde e Mar foi formada a partir dos atrativos naturais dos munícipios que a integram. Balneário Camboriú, sua municipalidade indutora, passou a atrair turistas para as cidades da destinação. Consequentemente, o fomento da região contribuiu para o seu desenvolvimento econômico, tornando-a importante para o desenvolvimento local (ESTADO DE SANTA CATARINA, 2011).

Costa Verde e Mar tem, além de Balneário Camboriú outras cidades importantes para a dinâmica do setor turístico, o que atrai centenas de visitantes dispostos a conhecer seus potenciais. Em função da ampla segmentação de mercado existente na destinação, ela se tornou ponto de referência em questão de diversidade sobre a prática do turismo. Contudo, apesar de a região ser conhecida por possuir diversos atrativos, alguns de seus municípios se encontram em uma área física muito vulnerável a desastres naturais: o Vale do Rio Itajaí (ESTADO DE SANTA CATARINA, 2009).

Dessa forma, Santa Catarina, além de apresentar elementos paisagísticos que afirmam sua aptidão para o turismo, também se encontra entre os estados da federação que mais possuem índice de catástrofes no Brasil (UFSC, 2013). Assim:

O estado registrou $12,2 \%$ de todos os desastres ocorridos no Brasil entre 1991 e 2010, apesar de representar apenas 1,2\% do território nacional [...]. Além disso, ele está no terceiro lugar do ranking (atrás do Rio Grande do Sul e Minas Gerais) onde mais ocorrem estes fenômenos (REQUEBI, 2012, p. 1). 
O gráfico 1 apresenta dados sobre esses fenômenos, contendo os desastres ocorridos no estado entre o período de 1991 a 2010 e abordando quais foram os tipos de desastres mais recorrentes no período analisado.

\section{GRÁFICO 1 - DESASTRES MAIS RECORRENTES EM SANTA CATARINA (1991 A 2010)}

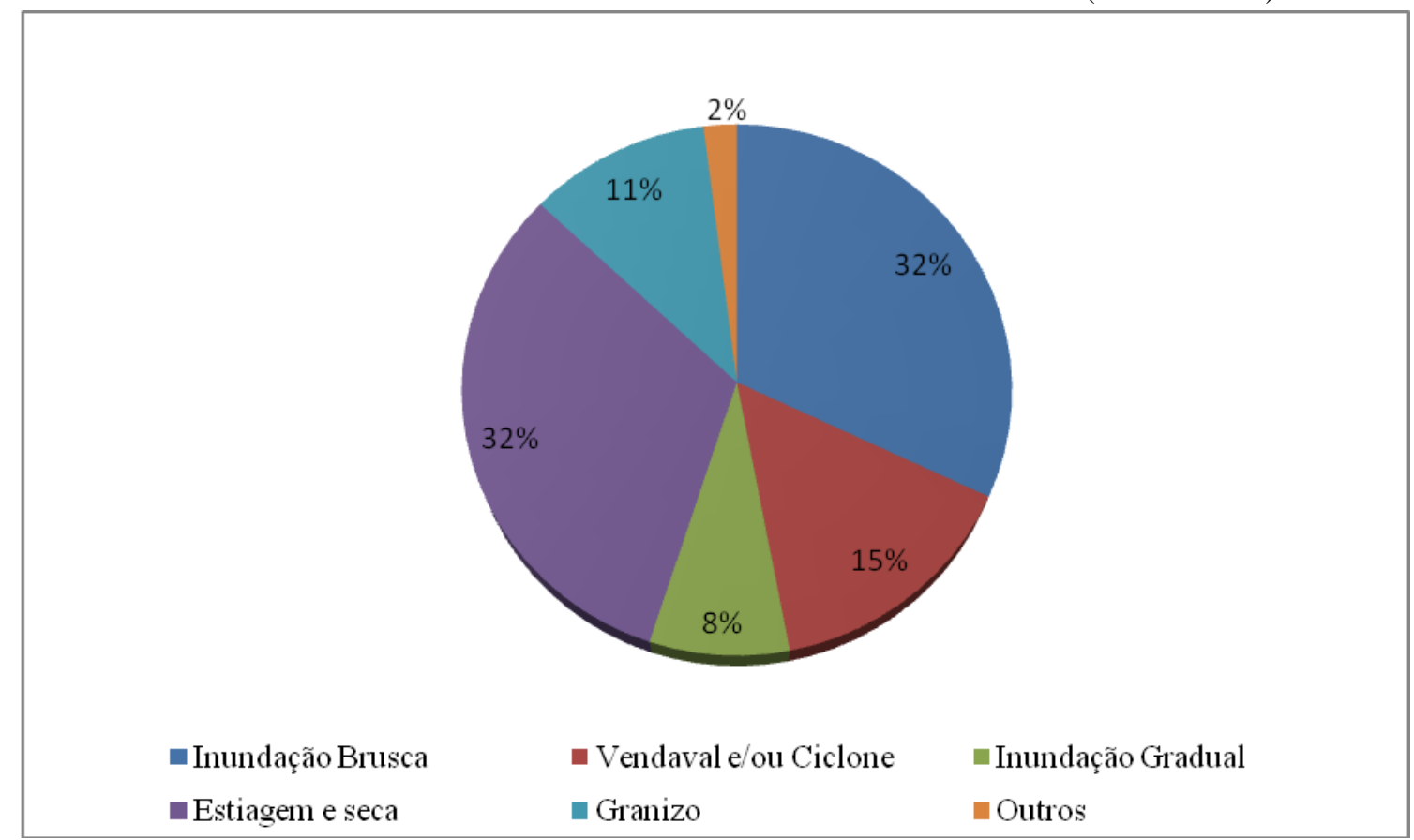

FONTE: UFSC (2013).

$\mathrm{Na}$ análise do gráfico, percebe-se que ao longo desse intervalo de tempo foram registrados diversos fenômenos associados a condições climáticas que proporcionaram os desastres no estado. Entre eles as inundações graduais, a estiagem prolongada, os vendavais, os ciclones e granizo. Inundações bruscas e estiagens foram os fenômenos mais recorrentes no estado, totalizando um percentual de $32 \%$ de ocorrência desse fenômeno ao longo do período analisado.

A seguir, o gráfico 2 apresenta dados sobre inundações bruscas e alagamentos em todas as regiões brasileiras ao longo do período analisado. 
GRÁFICO 2 - INUNDAÇÃO BRUSCA E ALAGAMENTO POR REGIÃO

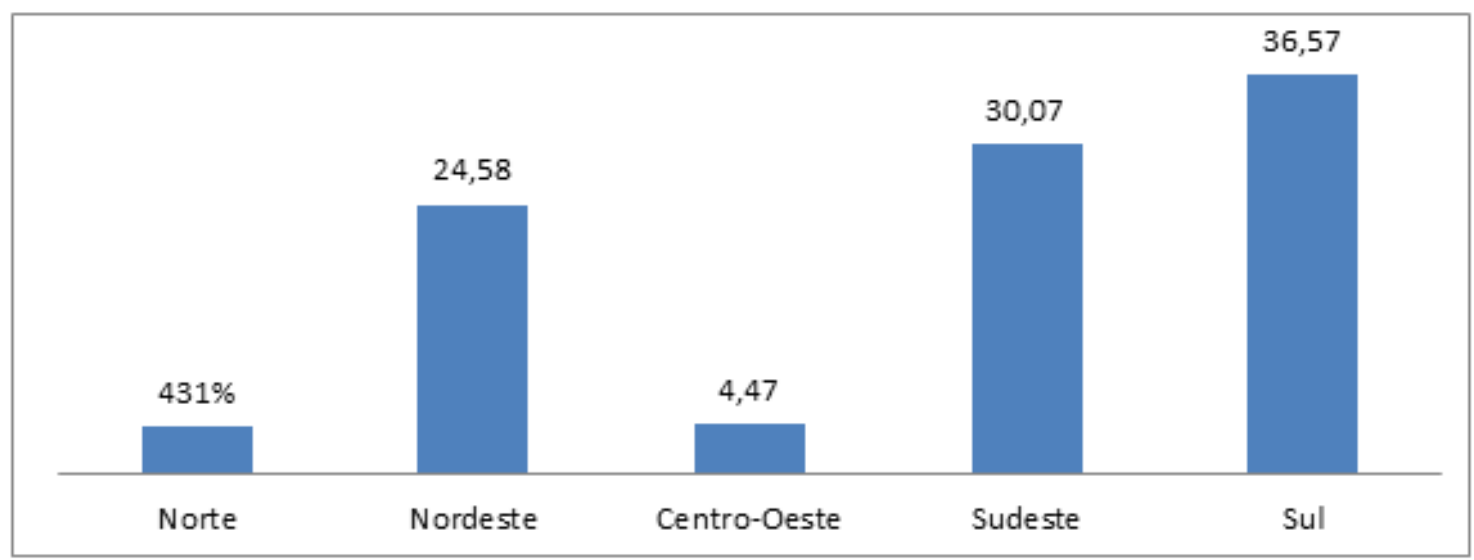

FONTE: UFSC (2013).

A leitura do gráfico mostra que a região sul é a mais afetada por esses tipos de desastres, com o estado de Santa Catarina sendo o mais afetado. As inundações bruscas e os alagamentos são registrados a partir do aumento da precipitação, no momento em que o limite de vazão de água é ultrapassado e o escoamento fica comprometido. Assim, quando a quantidade de chuva é elevada, o nível do rio aumenta, transvazando seu leito.

O gráfico 3, a seguir, apresenta dados sobre a frequência mensal de inundação brusca no estado de Santa Catarina, no mesmo período já analisado - de 1991 a 2010.

GRÁFICO 3 - FREQUÊNCIA MENSAL DE INUNDAÇÃO BRUSCA (1991 A 2010)

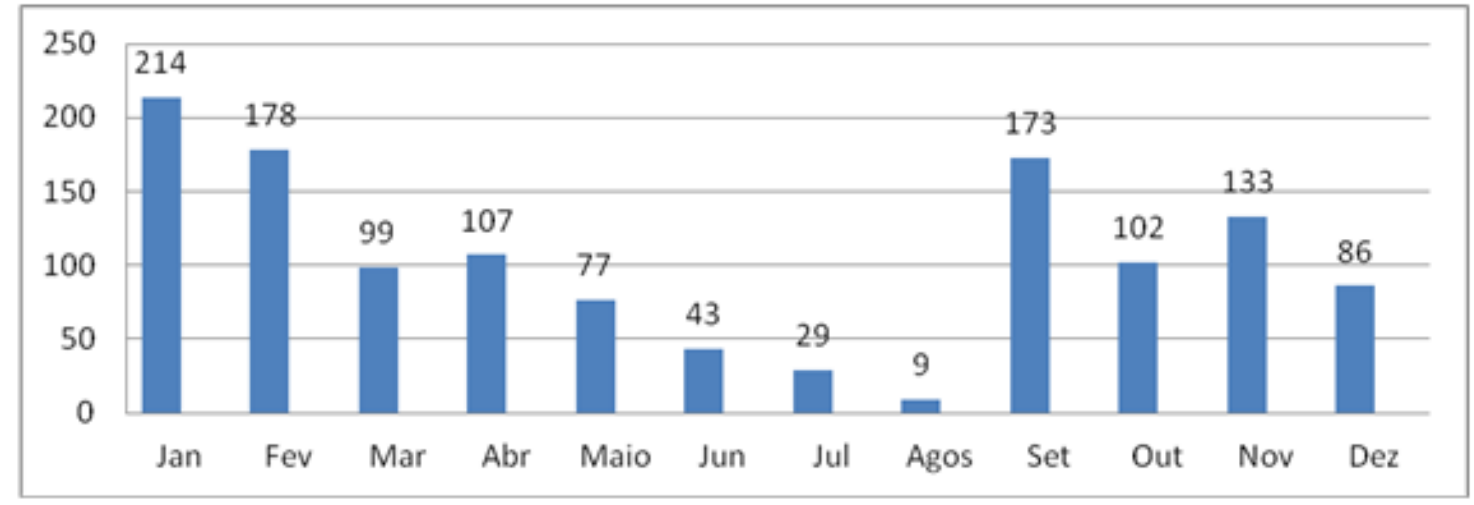

FONTE: UFSC (2013).

Os números acima demostram que o estado possui um grande problema quanto à questão das inundações bruscas. Os dados mostram também que entre os meses de setembro a março acontece a maior incidência de chuva no local. Segundo Monteiro 
$(2001)^{3}$ apud UFSC (2013), no verão em Santa Catarina a intensidade do calor, associada aos altos índices de umidade, favorece a formação de convecção tropical ${ }^{4}$, resultando em pancadas de chuva, principalmente no período da tarde e da noite, contribuindo com volumes significativos de água entre setembro e março.

A região da bacia hidrográfica do Vale do Itajaí vem apresentando um histórico de desastres. Ao longo do processo de colonização de Santa Catarina, o estado foi atingido por diversas tragédias associadas a fenômenos naturais. Assim, muitas regiões tiveram que se adaptar com seus impactos. No Vale do Itajaí, devido a condições físicas existentes no local, constituiu-se um alto grau de suscetibilidade à iminência de intempéries. Evidência disso é o fato de que, em um espaço curto de tempo, aconteceram dois fenômenos que atingiram integralmente o Vale, sendo um em 2008 e outro em 2011 (ESTADO DE SANTA CATARINA, 2009).

Nesse período, as chuvas intensas, devido ao alto nível de precipitação, provocaram uma série de devastações nas cidades que são cortadas pelo Rio Itajaí Açú, “obrigando quatorze munícipios catarinenses a decretar estado de calamidade pública e sessenta e três a decretarem situação de emergência" (ESTADO DE SANTA CATARINA, 2009, p. 7). “As regiões como o Médio e Baixo Vale do Itajaí sofreram de forma intensa com a força da natureza, deflagrando as inundações, alagamentos e os deslizamentos de encostas que trouxeram perdas de vidas humanas em algumas cidades" (ESTADO DE SANTA CATARINA, 2009, p. 8). Após o fenômeno, foram contabilizados "135 mortos, 78.656 desalojados e desabrigados, dos quais 27.404 desabrigados e 51.252 desalojados e 1,5 milhões de afetados" (ESTADO DE SANTA CATARINA, 2009, p. 8). Dessa forma, algumas cidades que integram a destinação Costa Verde e Mar, e que se encontram dentro da bacia hidrográfica do Vale do Itajaí, foram seriamente afetadas.

\footnotetext{
3 MONTEIRO, M. A. Caracterização climática do estado de Santa Catarina: uma abordagem dos principais sistemas atmosféricos que atuam durante o ano. GEOSUL, Florianópolis, v. 16, n. 15, p. 6978, jan.-jun. 2001.

${ }^{4}$ São muito comuns no verão em várias regiões do Brasil, ocorrendo principalmente no final da tarde. Ocorrem quando há intensa evaporação da água, provocada pelas altas temperaturas. Esta evaporação forma nuvens carregadas de umidade. Estas nuvens ganham altitude elevada, impulsionadas pelo movimento vertical do ar, onde ocorrem as precipitações (chuvas). As chuvas de convecção geralmente são rápidas (de meia a duas horas), porém intensas, ou seja, na forma de temporais. É muito comum na região Sudeste do Brasil, principalmente na estação do verão.
} 
A figura 2 mostra a bacia hidrográfica do Vale do Itajaí e suas microrregiões, sendo dividida em três: Alto, Médio e Baixo Vale do Itajaí.

FIGURA 2 - MAPA DA BACIA HIDROGRÁFICA DO RIO ITAJAÍ

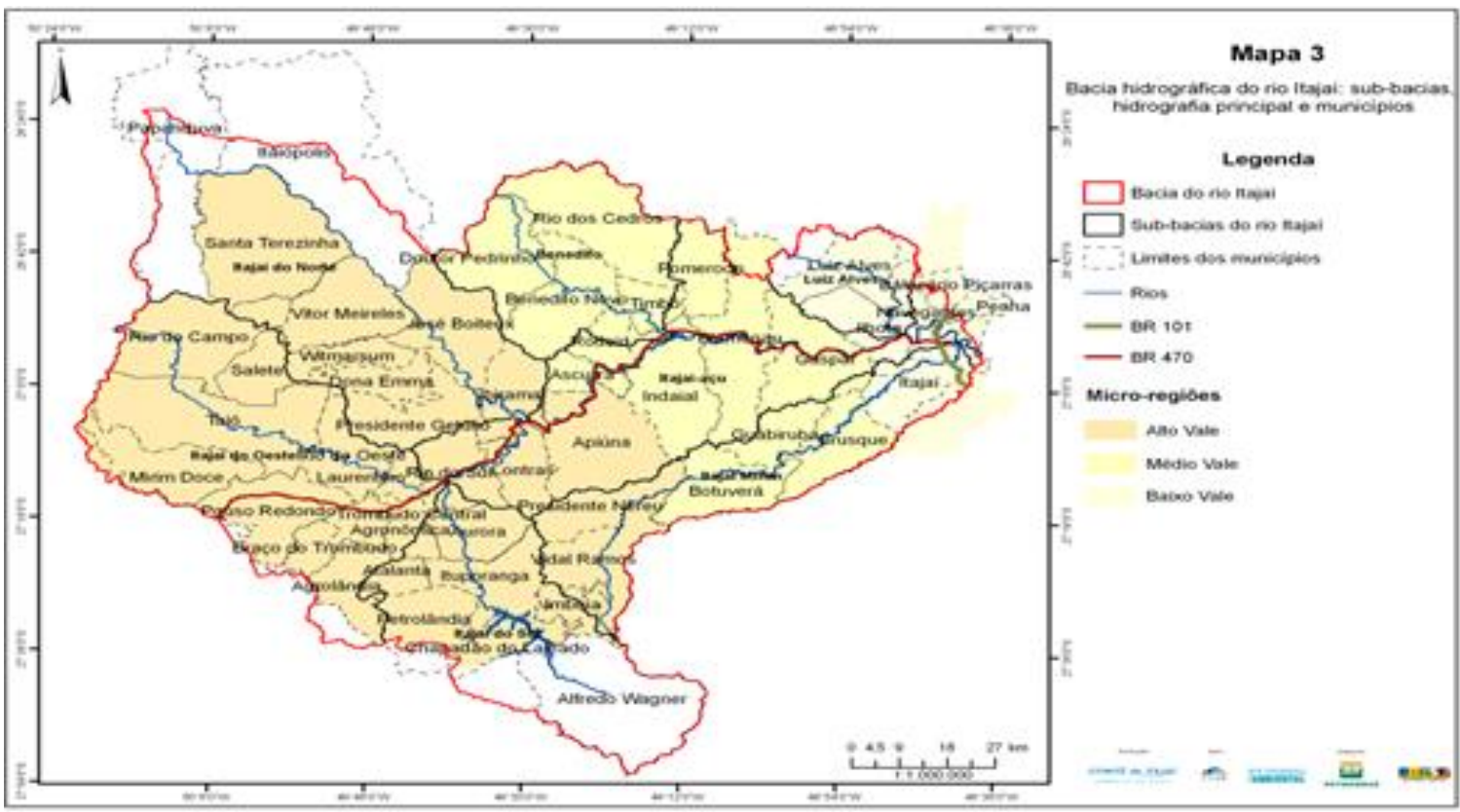

FONTE: Estado de Santa Catarina (2009).

Devido às características físicas, a região se constituiu com um alto grau de suscetibilidade a ocorrência de desastres. "Assim, municípios como Ilhota, Luís Alves, Itajaí e Navegantes possuem históricos de enchentes e alagamentos constantes" (ESTADO DE SANTA CATARINA, 2009, p. 7-8). Em função da suscetibilidade às intempéries devido às características geológicas da região, como o fato de ela estar em um Vale e em função de o Rio Itajaí Açú passar por toda a extensão da bacia, suas microrregiões sofrem com as interferências de intempéries relacionadas a fatores climáticos, "como o excesso de chuvas e também em virtude gestão ambiental praticada pelos municípios e as suas políticas urbanas são inadequadas ou inexistentes, o que explica a vulnerabilidade constatada" (ESTADO DE SANTA CATARINA, 2009, p. 9).

Segundo Guerra e Mendonça (2005), a intervenção humana sobre o relevo terrestre causa a ocupação e a transformação da paisagem. Dependendo do tipo de intervenção, das práticas conservacionistas utilizadas e dos riscos geomorfológicos envolvidos, os impactos ambientais poderão causar grandes prejuízos ao meio físico e à sociedade. Assim, as interferências de cunho antrópico na bacia hidrográfica, associadas a fatores físicos e climáticos, passaram a causar diversos impactos, tais como: 
alagamentos, enchentes e deslizamentos de encostas, que, com o passar dos anos, foram se tornando cada vez mais severos.

Segundo Estado de Santa Catarina (2009), a chuva desencadeou o desastre natural de 2008, mas foi a vulnerabilidade dos municípios diante de situações como essas que fez com que o evento assumisse a dimensão de tragédia. As estruturas de defesa civil municipais, a gestão ambiental praticada pelos municípios e as suas políticas urbanas são inadequadas ou inexistentes, o que explica a vulnerabilidade constatada. Na figura 3 podem-se ver os "municípios que decretaram situação de emergência e de calamidade pública no desastre de 2008 no Vale do Itajaí" (ESTADO DE SANTA CATARINA, 2009, p. 7) e que integram a destinação turística da Costa Verde e Mar.

FIGURA 3 - DISTRIBUIÇÃO DOS MUNICÍPIOS QUE DECRETARAM SITUAÇÃO DE EMERGÊNCIA E ESTADO DE CALAMIDADE PÚBLICA EM NOVEMBRO DE 2008

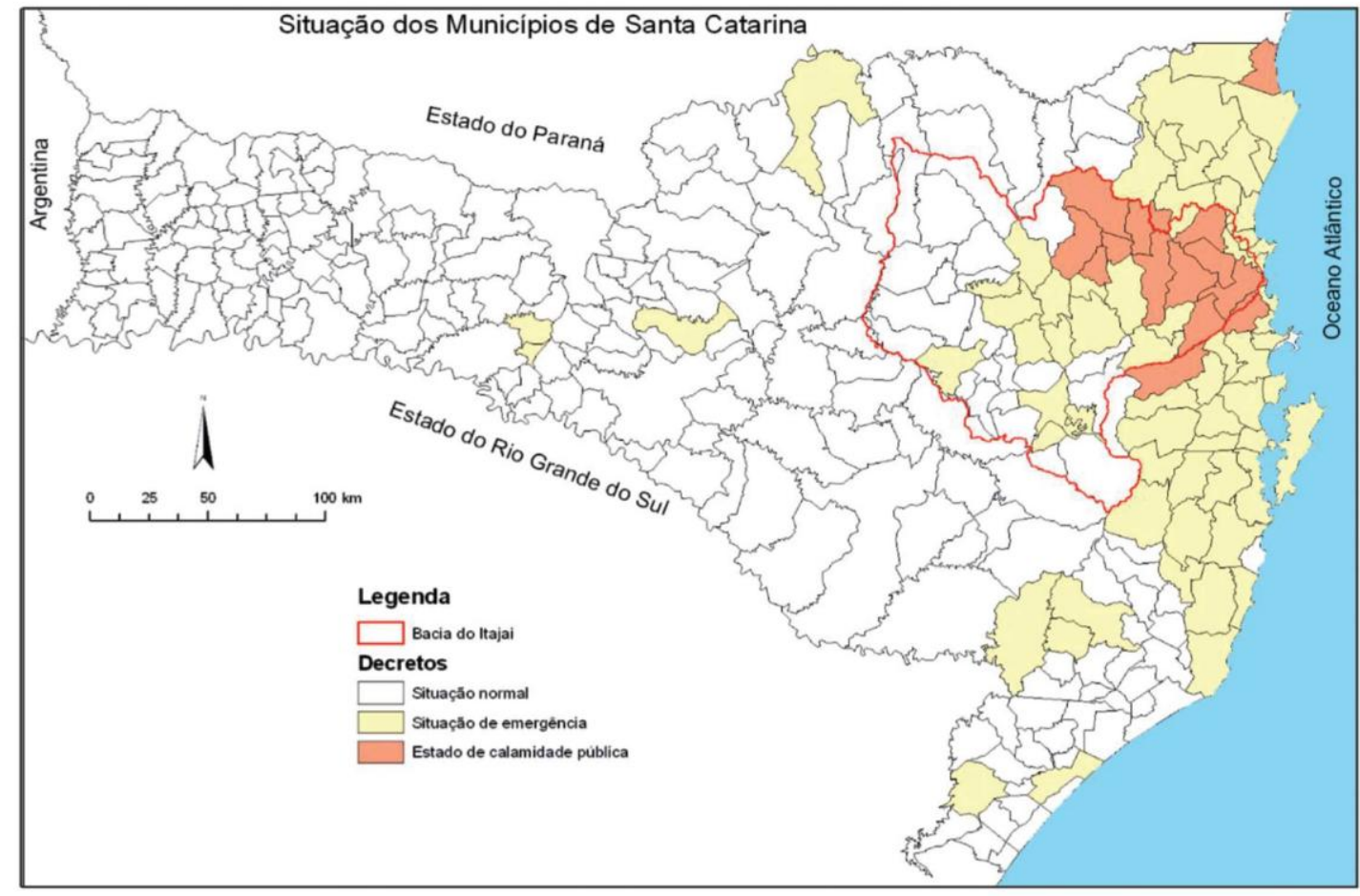

FONTE: Estado de Santa Catarina (2009).

Nota-se que os municípios localizados na microrregião do Baixo Vale, que integram essa destinação turística, tais como Itajaí; Luís Alves e Ilhota; e Camboriú, foram afetados e decretaram estado de calamidade pública (ESTADO DE SANTA CATARINA, 2009). As cidades que têm o turismo como uma fonte de renda e 
desenvolvimento, mas se encontram localizadas na microrregião, foram atingidas pela intempérie.

O fenômeno de novembro de 2008 foi de fato um conjunto de desastres, porque, além de enchentes e enxurradas, as chuvas intensas provocaram escorregamentos de encostas que, por sua vez, ocasionaram a destruição de muitas casas, edifícios, fábricas, escolas, lavouras, áreas de reflorestamento, pastagens e estradas, e seus impactos foram os mais percebidos e responsáveis pela maior parte das mortes (ESTADO DE SANTA CATARINA, 2009). Certamente, a chuva desencadeou o desastre, mas foi a vulnerabilidade dos municípios diante de situações como essas que fez com que o evento assumisse dimensão de tragédia (ESTADO DE SANTA CATARINA, 2009).

Pode-se afirmar que, mesmo com diversas tecnologias, várias comunidades, como a do Vale do Itajaí, ainda sofrem com a iminência de desastres e podem ser surpreendidas caso eles se efetivem, gerando prejuízos para as localidades afetadas. Essa relação entre desastre e território vem se tornando cada vez mais frequente, à medida que processos de interferências ocasionados pela ação antrópica sobre a dinâmica natural do ambiente se intensifica. De acordo com Mattedi e Butzke (2001), a ascensão do número de desastres nos últimos anos, mesmo em face de condições geofísicas relativamente estáveis, indica que o aumento da vulnerabilidade está intimamente conectado ao crescente processo de subdesenvolvimento e de marginalização social. Ainda segundo os autores, "os desastres são vistos como resultado da interface de uma população marginalizada e um ambiente físico deteriorado" (MATTEDI; BUTZKE, 2001, p. 14).

Constata-se que alguns municípios que têm economias alicerçadas no desenvolvimento turístico possuem problemas com alguns aspectos relacionados, por exemplo, à vulnerabilidade socioambiental, como a ocupação de áreas irregulares, a urbanização de margens de rios e áreas de preservação permanente. Assim, a partir do momento em que o desastre ocorrer, ele poderá trazer efeitos negativos em virtude das condições físicas existentes nos municípios e no Vale do Itajaí. "No evento ocorrido em 2008 foram afetadas algumas áreas econômicas de alguns municípios no setor público e privado, como, por exemplo, o Porto de Itajaí que foi afetado em função do desastre ocorrido" (ESTADO DE SANTA CATARINA, 2009, p. 9-10). Dessa forma, outros setores econômicos importantes para o desenvolvimento regional poderiam ter sido 
afetados por essa intempéries - como, por exemplo, o conjunto de infraestrutura e de equipamentos que compõem o trade turístico: meios de transporte (aéreo e terrestre), meios de hospedagem, setor de serviços como A\&B, lazer e entretenimento, dentre outros prestadores de serviços, o que proporcionaria sérios impactos, prejudicando toda a dinâmica do trade.

\section{CONSIDERAÇÕES FINAIS}

No presente estudo, a partir das concepções teóricas expostas, pretendeu-se contribuir com a apresentação e reflexão acerca da problemática que envolve os desastres, territórios e destinações turísticas, evidenciando o estudo de caso da Costa Verde e Mar, localizada no estado de Santa Catarina. Alguns municípios integrantes da destinação turística localizada na Bacia hidrográfica do Vale do Rio Itajaí Açú apresentam um alto grau de suscetibilidade a desastres naturais. Esses municípios sofreram, em 2008 e 2011, grandes impactos gerados por desastres naturais; isso fez com que alguns desses municípios decretassem estado de calamidade pública em decorrência das interferências provocadas por esse fenômeno.

Nesses dois eventos, o Vale do Itajaí foi atingido por uma grande quantidade de precipitação em um período curto de espaço/tempo, o que gerou enormes perdas para essas localidades. Esses impactos aconteceram em decorrência das características físicas da região, tais como: as geológicas, as geomorfológicas, as hidrológicas e as associadas a fatores humanos, como, por exemplo, as práticas ambientais inadequadas. Essas práticas, a partir de sua interação com fatores externos, como os de ordem climática, contribuíram para a ocorrência dos desastres.

Assim, os municípios de Itajaí, Ilhota, Luís Alves, Camboriú e Navegantes, os quais integram o Baixo do Vale do Itajaí, sofreram com enchentes, alagamentos, deslizamentos de encostas, entre outros. Esses municípios, que integram a destinação, encontram-se em destaque no âmbito estadual, pois são importantes economicamente para o estado, já que contribuem com o desenvolvimento regional. Para que futuros desastres não interfiram no desenvolvimento do setor turístico, a adoção de políticas públicas, através da gestão, que contemplem os desastres no turismo seriam uma 
importante ferramenta para fortalecer o setor, principalmente quando as regiões estivessem na iminência de sofrer alguma intempéries. A gestão dos desastres sobre a atividade do turismo se constituiria como prevenção para o setor e, principalmente, para os municípios que integram a destinação.

Dessa forma, a inclusão de um plano de contingência contra desastres, estabelecido nos alicerces do setor do turismo poderia subsidiar ações de cunho de gestão para o trade turístico existente na destinação. Assim, a adoção de políticas públicas proporcionaria um mecanismo de fortalecimento e de poder de resiliência em caso de crises e/ou interferências externas proporcionadas por esse fenômeno. Portanto, considera-se que a presente pesquisa sobre a destinação turística Costa Verde e Mar abre importantes discussões em relação à ocorrência de intempéries que podem causar prejuízos ao setor turístico.

A inclusão da gestão alicerçada nas políticas públicas sobre a atividade do turismo e os desastres naturais se torna importante para o desenvolvimento $\mathrm{e}$ continuidade do setor. Assim, o presente trabalho vem para evidenciar essa problemática e apresentar elementos que seriam importantes ao desenvolvimento de um plano de gestão à destinação turística, pois seriam essenciais em função das condicionantes apresentadas na Costa Verde e Mar. A abordagem sobre a destinação turística da Costa Verde e Mar se torna importante em função da ausência de estudos sobre essa temática e, bem como do fato de a destinação ser um dos pilares para o desenvolvimento regional, contribuindo para o crescimento dos municípios que a integram.

\section{REFERÊNCIAS}

BECKEN, S.; HUGHEY, K. F. D. Linking tourism into emergency management structures to enhance disaster risk reduction. Tourism Management, v. 36, p. 77-85, June. 2013.

ESTADO DE SANTA CATARINA. Plano Integrado de Prevenção e Mitigação de Riscos de Desastres Naturais na Bacia Hidrográfica do Rio Itajaí, 2009.

ESTADO DE SANTA CATARINA. Plano de Desenvolvimento Regional do Turismo do Estado de Santa Catarina Região Turística Costa Verde \& Mar2010/2020 (PDLI), 2011. 
FAULKNER, B. Towards a framework for tourism disaster management. Tourism Management, v. 22, I. 2, p. 135-147, April. 2001.

GHADERI, Z; MAT SOM, A. P; HERDERSON, J. C. Disaster Strikes: The Thai Floods of 2011 and Tourism Industry Response and Resilience. Asia Pacific Journal of Tourism Research, v. 20, I 4, p 399-415, February 2015.

GUimARÃES, R. M.; MAZOTO, M. L.; MARTINS, R. N.; CARMO, C. N. do; ASMUS, C. I. F. Construção e validação de um índice de vulnerabilidade socioambiental para a vigilância e gestão de desastres naturais no Estado do Rio de Janeiro, Brasil. Ciência e saúde coletiva, São Paulo, v. 19, n. 10, p. 4157-4165, Outubro 2014.

GUERRA, A. J. T.; MENDONÇA, J. K. S. Erosão dos solos e a Questão Ambiental. In: VITTE, A. C.; GUERRA, A. J. T. (Org.). Reflexões sobre a Geografia Física no Brasil. Rio de Janeiro: Bertrand Brasil, 2005 p. 225-256.

HYSTAD, P. W.; KELLER, P. C. Towards a destination tourism disaster management framework: Long-term lessons from a forest fire disaster. Tourism Management, v. 29, I 1, p. 151-162, February, 2008.

KOBIYAMA, M. Prevenção de desastres naturais: conceitos básicos. Curitiba: Organic Trading, 2006.

MATTEDI, M. A; BUTZKE, I. C. A relação entre o social e o natural nas abordagens de Hazards e de Desastres. Ambiente \& Sociedade, São Paulo, Ano IV, n. 9, p. 1-23, 2001.

MADITINIOS, Z.; VASSILIADIS, C. Local Crises and Natural Disasters: Effects and Consequences on the Global Tourism Industry. Thessaloniki, Grécia, 2008. Disponível em: $\quad$ http://mibes.teilar.gr/proceedings/2006/poster/MaditinosVassiliadis.pdf>. Acesso em: 20/04/2013.

NASCIMENTO, A. M. de V. do; ROCHA, L. K. S.; AZEVEDO, F. F. de; MORAIS, I. R. D. TURISMO E TRANSFORMAÇÕES SOCIOESPACIAIS: uma aproximação teórica e conceitual. Turismo \& Sociedade. Curitiba, v. 6, n. 2, p. 388-407, abril de 2013.

OURIQUES, H. R. A Produção do Turismo: Fetichismo e dependência. Campinas, SP: Alínea, 2005.

REQUEBI, A. Santa Catarina está entre os estados que mais registram desastres naturais. Diário Catarinense, Florianópolis, 25 maio. 2012. Disponível em: $<$ http://diariocatarinense.clicrbs.com.br/sc/geral/noticia/2012/05/santa-catarina-estaentre-os-estados-que-mais-registram-desastres-naturais-3767066.html>. Acesso em: 10/02/2014. 
SANSOLO, D. G. Centralismo e participação na proteção da natureza e desenvolvimento do turismo no Brasil. In: BARTHOLO JÚNIOR, R. S; SANSOLO, D. G; BURSZTYN, I. (Org.). Turismo de base comunitária: diversidade de olhares e experiências brasileiras. Rio de Janeiro: Letra e Imagem, 2009. p. 122-141.

SOLHA; K. T. Política de Turismo: Desenvolvimento e Implementação. In: RUSCHMANN, D; SOLHA, K. T. S.(Org.). Planejamento Turístico. Barueri/SP: Manole, 2006. p. 89-100.

TSAI, Chung-H; CHEN, Cheng-W. The establishment of a rapid natural disaster risk assessment model for the tourism industry. Tourism Management, v. 32, I 1, p. 158171, February. 2011.

TSAI, Chung-H; CHEN, Cheng-W. An earthquake disaster management mechanism based on risk assessment information for the tourism industry-a case study from the island of Taiwan. Tourism Management, v. 31, I. 4, p. 470-481, August. 2010.

TOUBES, D. R.; BREA FRAIZ, J. A. Desarrollo de uma politica de gestión de crises para desastres em el turismo. Tourism \& Management Studies, n. 8, p. 10-18, Out. 2012.

Gestión proactiva de crisis en el turismo: una experiencia de estudio en Galicia. Passos. Revista de Turismo y Patrimonio Cultural, n. 9, p. 279-289, 2011.

UFSC. UNIVERSIDADE FEDERAL DE SANTA CATARINA. Atlas brasileiro de desastres naturais: 1991 a 2010. 2. ed. Florianópolis: CEPED, 2013.

ZUCCO, F. D; MAGALHÃES, M. dos R. A. Gestão de Riscos e Desastres naturais no Turismo: um estudo do município de Blumenau/SC. Turismo em Análise, Balneário Camboriú, v. 21, n. 3, p. 594-620, Dezembro 2011.

Recebido em: 13-06-2016.

Aprovado em: 13-07-2016. 